\title{
Development of Marine Fibrinolytic Enzymes as a Resource for Novel Proteases and Their Roles in Fibrinolysis and Thrombolysis
}

\author{
Zibin Ma, ${ }^{a}$ Ming Ma, ${ }^{a}$ and Wenhui $\mathrm{Wu}^{*, a, b, c}$ \\ ${ }^{a}$ College of Food Science and Technology, Shanghai Ocean University, Shanghai 201306, China \\ ${ }^{b}$ Shanghai Engineering Research Center of Aquatic-Product Processing \& Preservation, Shanghai 201306, China \\ ${ }^{c}$ National Experimental Teaching Demonstration Center for Food Science and Engineering, \\ Shanghai Ocean University, Shanghai 201306, China
}

\begin{abstract}
Thrombosis is a serious disease of human health and life. Microorganism is an important source of fibrinolytic enzymes. The mechanism of action that it must combine with plasminogen to activate plasminogen of streptokinase is described. Herein, we summarize species characteristics and thrombolytic effects of fibrinolytic enzymes that are secreted from bacteria, actinomycetes and fungi. In recent years, more and more marine plasmin were found and used in thrombolytic test, displaying good fibrinolysis and thrombolysis.
\end{abstract}

Keywords microorganism, fibrinolytic enzyme, thrombolytic effect

\section{Introduction}

Thrombosis is a serious disease of human health and life, such as acute myocardial infarction (AMI) and venous thrombus embolism (VTE). Nowadays, thrombolytic therapy is a common treatment method for the heart muscle infarction and other thrombolytic disease.

Thrombosis is a small blot of blood that is formed on the surface of the vessel lining or the repair cardiovascular system. In variable flow dependent patterns, thrombus is composed of insoluble fibrous proteins, deposited platelets, accumulated white blood cells and trapped red blood cells. Thrombosis is a multivariate process of interaction and interaction between a set of genetic and environmental factors. There are three main mechanisms of thrombosis: Firstly, damage of intima of heart and blood vessel. (1) When the lining is damaged, the endothelial cells are transgendered and necrotic and the skin is exposed to collagen. To activate the endogenous clotting system XII factor, endogenous clotting system is activated. (2) The tissue coagulation factor which releases by damaged intima can activate exogenous coagulation system. (3) The damaged intima becomes coarse, making platelets easy to aggregate. Secondly, hemodynamic change. The blood flow slows and the blood forms vortex. Thirdly, blood change. Increased coagulation of blood was found in the increase of platelets and coagulation factors.

Thrombolysis refers to degrade thrombosis by enzymatic reaction. When a clot is formed in the body, the plasminogen $(\mathrm{Pg})$ in the blood is partially enriched to the thrombus because of its affinity for fibronectin (fn). Plasminogen activation (pA) can activate Pg to plasmin $(\mathrm{Pm})$ and $\mathrm{Pm}$ with the activity of serine protease can degrade the fn that forms the thrombus skeleton. Thus it can degrade the thrombosis. There are three types of drugs that can prevent clots. The first is anticoagulants whose main function is to prevent blood clotting. The second is antiplatelet aggregation drugs in which a receptor antagonist of platelet glycoprotein II b/III is an important milestone of antiplatelet therapy. The third is thrombolytic drugs which can act on Arg-Lys to decompose fibrous protein into a soluble product. It contains two main kinds, streptokinase (SK) and urokinase (UK). SK can combine with Pg to form SK-Pg which can activate Pg into Pm and degrade thrombosis finally. UK can immediately act on Pg and form $\mathrm{Pm}$ to hydrolyze for $\mathrm{fn}$.

\section{Streptokinase $\mathrm{e}^{[1-3]}$ as a classical fibrinolytic en- zyme from Streptococcus}

Streptokinase, a protein secreted by several species of streptococci can bind and activate human plasminogen. streptokinase is used as an effective an inexpensive thrombolysis medication in some cases of myocardial infarction (heart attack) and pulmonary embolism. SK belongs to a group of medications known as fibrinolytic, and complexes of streptokinase with human plasminogen can hydrolytically activate other unbound plasminogen by activating through bond cleavage to produce plasmin.

Streptokinase is an extracellular bacterial protein produced by several strains of Streptococcus haemolyticus group C, and it is also secreted by Streptococcus equisimilis, pathogenic strains of streptococcus.

Streptokinase, an important thrombolytic protein, displays a molecular mass in the region of $45-48 \mathrm{kD}$ and an isoelectric point of 4.7. Streptococcus equisimilis streptokinase is a single-chain protein of 414 residues. Streptokinase is composed of three structurally autonomous domains, which are homologous, independently folded, and connected by flexible linking segments, with a C-terminal "tail" that is relatively unstructured. In solution, free streptokinase is highly flexible, with the three domains able to assume many different conformations due to the linking sequences. The three domains of streptokinase are denoted $\alpha$ (residues 1-150), $\beta$ (residues 151-287), and $\gamma$ (residues 288-4140). Each domain binds plasminogen, although none can activate plasminogen independently. All of streptokinase's three domains are essential for native-like streptokinase activity. The central and C-terminal domains mediate plasmnogen-binding and active site-generating function, whereas the $\mathrm{N}$-terminal domain mediates an activity-potentiating function. Streptokinase is used extensively in the clinical treatment of acute myocardial infarction due to its ability to

\footnotetext{
* E-mail: whwu@shou.edu.cn

Received December 6, 2017; accepted December 28, 2017.
} 
activate human plasminogen.

Streptokinase is a potent activator of the fibrinolytic enzyme system, in humans streptokinase binds to plasminogen and generates a streptokinase-plasminogen activator complex. This complex catalyzes the conversion of plasminogen to plasmin, an active enzyme that degrades the fibrin component of thrombin: binding specifically and tightly to plasminogen; inducing conformational change in the plasminogen molecule; redering it proteolytically active.

Streptokinase secreted by Streptococcus equisimilis activates the human fibrinolytic system by converting the zymogen, plasminogen (Plg) into the clot-dissolving proteinase, plasmin (Pm). This activity is the basis for the use of streptokinase as a thrombolytic drug for treatment of myocardial infarction. Streptokinase activates $\mathrm{Plg}$ by a unique mechanism initiated by rapid and reversible formation of an $\mathrm{SK}-\mathrm{Pg}$.

\section{Marine fibrinolytic enzymes from marine organ- ism}

Bacteria, fungi and actinomycetes have the ability to produce fibrinolytic enzymes, especially bacteria which have many kinds. The streptokinase secreted by Streptococcus hemolyticus and staphylokinase (SaK) secreted by Staphylococcus aureus are found earlier which is produced through bacteria. In recent years, there are more and more kinds of fibrinolytic bacteria found. Most of them are marine microorganism. Kim et al. ${ }^{[11]}$ separated and purified a kind of plasmin which molecular weight is $28.2 \mathrm{kD}$ and secreted by Bacillus Sp.CK-114. Oaks Walton et al. ${ }^{[12]}$ extracted a medium-type endodermal fibrinolytic enzyme streptococcus faecium, which molecular weight is $19 \mathrm{kD}$. Poonam et al. ${ }^{[51]}$ reported a low molecular weight chymotrypsin-like novel fibrinolytic enzyme from Streptomyces sp. CS624. Wang et al. ${ }^{[13]}$ also extracted a kind of plasmin SW-1 which molecular weight is $30 \mathrm{kD}$. It is important to note that the same fermentation is often caused by the diversity of bacterial strains and the diversity of fibrinolytic enzymes. In China, the Bacillus amyloliquefaciens DC-4 can produce DFE, ${ }^{[14]}$ Bacillus subtils DC3 can secrete FS33. ${ }^{[15]}$ In Korea, the Bacillus sp.CK11-4 can secrete CK, ${ }^{[16]}$ and the Bacillus vallismortis Ace02 can extract Ace02. ${ }^{[17]}$ Liu et al. ${ }^{[18]}$ reported on a marine Pseudomonas sp., which can produce a strong alkaline protease MPAP that can directly dissolve fibrous protein and antithrombotic formation. Ae et al. ${ }^{[52]}$ studied on the characterization of a $27 \mathrm{kDa}$ fibrinolytic enzyme from Bacillus amyloliquefaciens CH86-1 isolated from Cheonggukjang. Li et al. ${ }^{[19]}$ reported a marine microorganism B5815, which can produce plasmin. Han et al. ${ }^{[53]}$ detected a unique fibrinolytic enzyme in Aeromonas sp. JH1. Huang et al. ${ }^{[20]}$ found a marine strain HQS-3 with high fibrinolytic enzyme activity.

Won et al. ${ }^{[54]}$ showed biochemical analysis of a fibrinolytic enzyme purified from bacillus subtilis strain A1. Wang et al. ${ }^{[21]}$ studied on anticoagulant and thrombolytic effects of a novel marine fibrinolytic enzyme in vitro. The results showed that there were apparent anticoagulant effect as well as thrombolytic effects in the self-made marine fibrinolytic enzymes, and the status of the released blood cells from thrombus using this enzyme was also better than that of using lumbrukinase. Aungkawipa et al. ${ }^{[55]}$ reported novel fibrinolytic enzymes from Virgibacillus halodenitrificans SK1-3-7 isolated from fish sauce fermentation. Li et al. ${ }^{[22]}$ reported a marine Bacillus subtilis which produces fibrinolytic enzyme was mutagenesis by ultraviolet (UV). A mutant (Y-22) contained high fibrinolytic activity was obtained. It was stable after several generations. Ratnakar et al. ${ }^{[56]}$ studied on production, purification, and biochemical characterization of a fibrinolytic enzyme from Thermophilic Streptomyces sp. MCMB-379. Liu et al. ${ }^{[23]}$ studied a kind of plasmin which extracted from Urechis Unicinctus. The result of fibrinolytic test shows that UFE owns kinase activity and apparent fibrinolytic effection and conclusion was achieved that UFE1 possesses significant effect on anticoagulability and antithrombotic activity, which induces a temporary rise of specific antibodies in mice, but does not affect adversely on animal bodies. Chen et al. ${ }^{[57]}$ did the research on purification and biochemical properties of a fibrinolytic enzyme from Bacillus subtilis fermented red bean. Wu et al. ${ }^{[24-27]}$ reported that three small molecular compounds with fibrinolytic facilitation were obtained from the metabolites of algae and microorganisms. The compound is not the enzyme, but it has showed excellent fibrinolytic facilitation in the simulated reaction system, and its thrombolytic promoter was confirmed from animal models. Jo et al. ${ }^{[58]}$ introduced purification and characterization of a major fibrinolytic enzyme from Bacillus amyloliquefaciens MJ5-41 isolated from Meju.

The fibrinolytic molecular weight of discovered from microbial is generally between 21 and $40 \mathrm{kD}$. The molecular weight of Bacillus is concentrated in about $28 \mathrm{kD}$. Occasionally the enzyme has a higher molecular weight, such as Jeot-Ga, ${ }^{[28]}$ whose molecular weight is 41 $\mathrm{kD}, \mathrm{SK} 006^{[29]}$ whose molecular weight is $43-46 \mathrm{kD}$ and the plasmin of Cordyceps militaris ${ }^{[30]}$ is $52 \mathrm{kD}$. Most of these fibrinolytic enzyme in less than $40{ }^{\circ} \mathrm{C}$ and weak alkaline environment is stable and highest energy. The fibrinolytic enzyme produced by Streptomyces megasporus $\mathrm{SD}^{[31]}$ which is isolated from hot spring has highest enzyme activity in $55{ }^{\circ} \mathrm{C}$ and in $70{ }^{\circ} \mathrm{C}$ it can has half. $\mathrm{Ca}^{2+}$ plays an important role in keeping the stability of the enzyme. The origin and properties of some fibrinolytic enzymes are shown in Table 1.

\section{Fibrinolysis of marine fibrinolytic enzymes}

Microbial fibrinolytic enzymes have two different mechanisms: One type is indirect degradation of fibrin by activating fibrinolytic enzyme, such as SK, Sak, BKII; another type can directly degrade fibrous protein, such as SW-1, DFE and QK. Fu et al. ${ }^{[4]}$ reported fibrinolysis promoting activity of a novel metabolic product of marine microbe-FGFCl which is not enzyme. The study showed FGFC1 has excellent fibrinolysis promotion. Madhuvanthi et al. ${ }^{[59]}$ did the research on thrombolysis by rt-PA in a human whole-blood in vitro clot model. Sun et al. ${ }^{[5]}$ studied on the ufeII which is extracted from Urechis unicinctus and showed better action on fibrinolysis. Jun et $a l .{ }^{[60]}$ reported thrombolytic effects of fibrinolytic enzyme from Bacillus subtilis LD-8547 in vitro and in vivo, which has obvious thrombolytic effects in vitro and in vivo. This function demonstrates that this enzyme can be a useful tool for preventing and treating clinical thrombus. Liu et al. ${ }^{[6]}$ studied on thrombolytic experiment of marine pseudomonas fibrinolytic enzyme in vitro. It is a direct fibrinolytic enzyme with strong fibrinolytic activity. Wang et al. ${ }^{[21]} \mathrm{stu}-$ died on thrombolytic effects of a novel marine fibrinolytic enzyme in vitro. The results showed it has better fibrinolytic activity. MPAP, ${ }^{[35]}$ which is an alkaline protease secreted by marine pseudomonas, can significantly inhibit platelet aggregation and be beneficial to inhibit the formation of thrombus, showing excellent fibrinolytic activity. Ace $02^{[36]}$ can kill Streptoccus mutans, which is the main pathogenic bacteria of tooth decay. Myulchi can inhibite the tumor and has no effect on the activity of normal thymic epithelial cells MCF $10 \mathrm{~A}^{[37]}$ More and more plasmin is found from marine microorganism, but data on the use of effects and safety in the human body is still fairly limited or lacking. The study of marine microbial fibrinolytic enzyme of thrombolytic specificity, pharmacological experiments and clinical trials in vitro is more urgently needed.

\section{Thrombolysis of marine fibrinolytic enzymes}

In animal experiments, creatinekinase (CK) of proteinkinase has been shown to be an ideal thrombolytic effect. The study found that thrombolytic activity of SK can last more than $3 \mathrm{~h}$ in the blood. ${ }^{[34]}$ In addition to thrombolytic, some fibrinolytic enzymes are also found to have other pharmacological effects. Fu et al.$^{[4]}$ reported fibrinolysis promoting activity of a novel metabolic product of marine microbe- 
Table 1 Comparison of species and characteristics of fibrinolytic compound ${ }^{[32]}$

\begin{tabular}{|c|c|c|c|c|c|}
\hline Organism & Producing strain & Enzyme & Molecular weight & $N$-terminal AA & Ref. \\
\hline \multirow[t]{9}{*}{ Bacillus } & Pseudomonas sp. & MPAP & $21 \mathrm{kD}$ & No data & [18] \\
\hline & Bacillus sp.KA38 & subtilisin FS33 & No data & VYPFPGPIPN & [9] \\
\hline & Bacillus sp. CK11-4 & $\mathrm{CK}$ & $28.2 \mathrm{kD}$ & AQTAPYGIPLIKAD & [10] \\
\hline & Staphylococcus sp.AJ & AJ & $26 \mathrm{kD}$ & VILPNNXRHQIFXTTQG & [38] \\
\hline & Bacillus subtilis QK02 & subtilisin QK & $28 \mathrm{kD}$ & $\begin{array}{l}\text { AQSVPYGISQIKA- } \\
\text { PALHSQG }\end{array}$ & [40] \\
\hline & Bacillus sp.DJ-4 & & $29 \mathrm{kD}$ & AQSVPYGVSQIKAP & [41] \\
\hline & Bacillus subtilis natto & nattokinase & $27.7 \mathrm{kD}$ & AQSVPYGISQIKAPALHS & [42] \\
\hline & Bacillus vallismortis Ace 02 & Ace02 & $28 \mathrm{kD}$ & AQSVPYGVSQ & [43] \\
\hline & Streptomyces sp.Y405 & SW-2 & $30 \mathrm{kD}$ & $\begin{array}{c}\text { R/N/FP/DGMTMTAIANQN } \\
\mathrm{T}\end{array}$ & [44] \\
\hline \multirow{2}{*}{ Actinomycetes } & Streptomyces megasporus & & $35 \mathrm{kD}$ & No data & [46] \\
\hline & Rhizopus chinesis $12 \#$ & & $18 \mathrm{kD}$ & SVSEIQLMHNLG & [47] \\
\hline \multirow[t]{5}{*}{ Fungi } & Cordyceps militaris & CMas & $27.3 \mathrm{kD}$ & IVGGVSVAIE & [48] \\
\hline & Armillaria mellea & AMMP & $21 \mathrm{kD}$ & MFSLSSRFFLYTLCLSAVA & [49] \\
\hline & Flammulina velutipes & FVP-1 & $37 \mathrm{kD}$ & $\begin{array}{c}\text { LTYRVIPITKQAVTEG- } \\
\text { TELL }\end{array}$ & {$[50]$} \\
\hline & Fusarium sp.BLB & $\begin{array}{l}\text { Fusarium en- } \\
\text { zyme }\end{array}$ & $27 \mathrm{kD}$ & IVVGTTAASGGDFPIIVSI & [9] \\
\hline & Stachybotrys longispora FG216 & FGFC1 & 869Da & No data & {$[10]$} \\
\hline Other & Urechis Unicinctus & UFE-II & $26 \mathrm{kD}$ & ICGGSPADIT & [7] \\
\hline
\end{tabular}

FGFC1 showed excellent thrombolysis effects. Qu et al. ${ }^{[8]}$ reported dissolving effect of marine pseudomonas alkaline protease on the arterial thrombus of experimental rabbits. The results showed MPAP has certain solubility to the experimental rabbit femoral artery thrombosis and has obvious anticoagulant function. Wang et al..$^{[21]}$ also studied on thrombolytic effects of a novel marine fibrinolytic enzyme in vivo. The results showed that there were apparent anticoagulant effect as well as thrombolytic effects in the self-made marine fibrinolytic enzymes, and the status of the released blood cells from thrombus using this enzyme was also better than that of using lumbrukinase. It has better thrombolysis activity. Chu et al. ${ }^{[7]}$ studied on UFE-I which extracted from Urechis unicinctus. The results showed it has excellent thrombolytic action. Through the above study, we find more and more thrombolytic drugs which are secreted by marine organism and they have excellent thrombolysis activity. Currently, thrombolytic drugs produced by marine organism (especially marine microorganism) have become a research hotspot.

\section{Conclusions}

As the thrombosis becomes more serious, there are millions of patients dying of thrombosis every year. ${ }^{[33]}$ It is very important to research on the mechanism and application of thrombolytic enzyme. The ideal thrombolytic enzyme should possess several advantages of high enzyme activity, long efficacy, low cost and safety. In order to discover and get new natural thrombolytic enzyme using biological techniques such as modern structural biology and enzyme engineering, it is the future research direction to elucidate its mechanism and solve the difficulties of its preparation. In addition, with the use of molecular biology techniques to assemble the advantages of the existing thrombolytic enzyme, it is the development and basic research to design thrombolyases that meet the clinical needs.

\section{Acknowledgments}

The work was supported by the National Natural Science Foundation of China (No. 81502955), the Doctoral Scientific Research Foundation of Shanghai Ocean University (No. A2030214300077), the Young Teachers Training Program of Shanghai (No. A12056160002), the Plan of Innovation Action in Shanghai (No. 14431906000), and the Project Funded by Jiangsu Key Laboratory of Marine Pharmaceutical Compound Screening.

\section{References}

[1] Ding, H.; Zhu, S. S. Chin. J. Biotechnol. 1994, 10, 56.

[2] Gulga, C.; Bode, M. S.; Runge, K. H. Fibrinolysis \& Protelysis 1998, 12,39 .

[3] Wang, C. X. BIOLOGICS, Beijing, 2014, pp. 207-209.

[4] Fu, S. Q.; Yan, T.; Wu, W. H. Pharm. Care Res. 2015, 15, 99.

[5] Sun, X. Y.; Song H. X. CSP 2016, 24, 2797.

[6] Liu, C. G.; Wang, P. Chin. J. Biochem. Pharm. 2002, 1, 34.

[7] Chu, J. X.; Cai, W. D.; Han, B. Q.; Liu, W. S. Pharm. Biotechnol. 2010, 4, 331.

[8] Qu, Z. L.; Liu S.; Dong, H.; Liu, C. G.; Liu, W. S. Chin. J. Mar. Drugs $\mathbf{2 0 0 5}, 3,10$.

[9] Ueda, M.; Kubo, T.; Miyatake, K. Appl. Microbiol. Biotechnol. 2007, 74, 331.

[10] Wang, G.; Wu, W. H.; Zhu, Q. G.; Fu, S. Q.; Wang, X. Y.; Hong, S. T.; Guo, R. H.; Bao, B. Chin. J. Chem. 2015, 8, 1.

[11] Wonkeuk, K.; Keehyun, C. AEM 1996, 62, 2482.

[12] Richard, A. G. $A B B$ 1980, 202, 629.

[13] Wang, M.; Wang, J. Acta Pharm. Sin. 1997, 33, 481.

[14] Peng, Y.; Huang, Q.; Zhang, R. H. Biochem. Mol. Biol. 2003, 134, 45.

[15] Wang, C. T.; Ji, B. P.; Li, B. Ind. Microbiol. Biotechnol. 2006, 33, 750.

[16] Kim, W.; Choi, K.; Kim, Y. AEM 1996, 62, 2482.

[17] Kim, J. B.; Jung, W. H.; Ryu, J. M. Biotechnol. Lett. 2007, 29, 605.

[18] Liu, C. G.; Wei, X.; Liu, W. S. J. Ocean Univ. China 2001, 31, 730. 
[19] Li, Z. Q.; Hu, J. C.; Pan, H. Q.; Wang, S. J. J Microbiol. 2009, 29, 41.

[20] Huang, S.; Li, J. Q.; Zhang, Y. K. Food Sci. Technol. 2009, 34, 19.

[21] Wang, D. L.; Liu, W. S.; Han, B. Q. Chin. J. Mar. Drugs 2006, 25, 37.

[22] Li, Y.; Zhang, Z. F.; Tian, M. China Brewing 2012, 31, 33.

[23] Liu, W. S.; Cheng, H. Z.; Han, B. Q. J. Ocean Univ. China 2012, 4, 88.

[24] Wu, W. H.; Bao, B. J. Food Sci. 2005, 26, 34.

[25] Zhang, Y.; Wu, W. H.; Zhou, P. G.; Bao, B. Chin. J. Mar. Drugs 2008, 27, 39.

[26] Wen, W.; Rituko, N.; Bunnkenn, M.; Hasumi, K. Biosci. Biotechnol. Biochem. 2004, 68, 1549.

[27] Wu, W. H.; Keiji, H.; Peng, H.; Wang, X. C.; Bao, B. J. Chin. Mar. Drugs 2009, 7, 85 .

[28] Kim, H. K.; Kim, G. T.; Kim, D. K. J. Ferment Boeing. 1997, 84, 307.

[29] Hua, Y.; Jiang, B.; Mine, Y. J. Agric. Food Chem. 2008, 56, 1451.

[30] Kim, J. S.; Sapkota, K.; Park, S. E. J. Microbiol. 2006, 44, 622.

[31] Chitte, R. R.; Dey, S. Appl. Microbiol. 2000, 31, 405.

[32] Weng, Y. H.; Yang, X. T.; Yang, M. J.; Yang, Q. Y. Prog. Modern Biomed. 2010, 10, 1562.

[33] Wang, S. H.; Hu, K. H.; Sha, L. Food Sci. Technol. 2006, 22, 174

[34] Tai, M. W.; Sweet, B. V. Am. J. Heal System Pharm. 2006, 63, 1121.

[35] Qu, Z. L.; Liu, S.; Liu, C. G. Acta Academiae Medicinae Qingdao Universitatis 2003, 39, 156.

[36] Kim, J. B.; Jung, W. H.; Ryu, J. M. Biotechnol. Lett. 2007, 29, 605.

[37] Jeong, Y. K.; Yang, W. S.; Kim, K. H. Biotechnol. Lett. 2004, 26, 393.

[38] [38] Choi, N. S.; Song, J. J.; Chung, D. M. J. Ind. Microbiol. Biotechnol. 2009, 36, 417.

[39] Wang, S. L.; Chen, H. J.; Liang, T. W. Process Biochem. 2009, 44, 70

[40] Kong, J. H.; Yan, J, P. Zhu, L. Toxicol. Pharmacol. 2004, 137, 65.

[41] Kim, S. H.; Choi, N. S. Biosci. Biotechnol. Biochem. 2000, 64, 1722.

[42] Fujita, M.; Nomura, K.; Hong, K. Biochem. Biophys. Res. Commun. 1993, 197, 1340 .

[43] Kim, J. B.; Jung, W. H.; Ryu, J. M. Biotechnol. Lett. 2007, 29, 605.
[44] Wang, J.; Wang, M.; Wang, Y. G. Chin. J. Biotechnol. 1999, 15, 147.

[45] Bono, F.; Savi, P.; Tuong, A. Fems Microbiol. Lett. 2010, 141, 213.

[46] Chitte, R. R.; Dey, S. Appl. Microbiol. 2000, 31, 405.

[47] Liu, X. L.; Du, L. X.; Lu, F. P. Appl. Microbiol. Biotechnol. 2005, 67, 209.

[48] Cui, L.; Dong, M. S.; Chen, X. H. World J. Microbiol. Biotechnol. 2008, $24,483$.

[49] Lee, S. Y.; Kim, J. S.; Kim, J. E. Protein Express Purif. 2005, 43, 10.

[50] Park, S. E.; Li, M. H.; Kim, J. S. Biosci. Biotechnol. Biochem. 2007, 71, 2214.

[51] Poonam, M.; Seung, S. C.; Jaya, R. S.; Yun, H. C.; Jin, C. Y. Process Biochem. 2011, 46, 1449.

[52] Ae, R. L.; Gyoung, M. K.; Jae, Y. P.; Hyeon, D. J.; Jaeho, C.; Y, S. S.; Jiyeon, C.; Jeong, H. K. J. Korean Soc. Appl. Biol. Chem. 2010, 53, 56.

[53] Han, Y. C.; Min, J. S.; Jeong, U. P.; Byoung, W. K.; Gi, Y. K.; Woo, H. J.; Young, C. L.; Young, S. C.; Yong, K. J. J. Microbiol. 2011, 49, 1018

[54] Won, S. K.; Min, J. S.; Min, J. K.; Hye, H. L.; Byoung, W. K.; Jeong, U. P.; Yung, H. C.; Yong, K. J. J. Microbiol. 2011, 49, 376.

[55] Aungkawipa, M.; Sasitorn, K.; Sureelak, R.; Sittirak, R.; Jirawat, Y. Process Biochem. 2012, 47, 2379.

[56] Ratnakar, R. C.; Siddharath, V. D.; Pradnya, P. K. Appl. Biochem. Biotechnol. 2011, 165, 1406

[57] Chen, T. C.; Pei, M. W.; Ya, F. H.; Yun, C. C. Food Chem. 2012, 133, 1611 .

[58] Jo, H. D.; Hwang, A. L.; Seon, J. J.; Jeong, H. K. J. Microbiol. Biotechnol. 2011, 21, 1166.

[59] Madhuvanthi, A. K.; Jason, M.; Christopher, J. L.; George, J. S.; Mitchell, S. V. E. Curr. Neurovas. Res. 2012, 9, 207.

[60] Yuan, J.; Yang, J.; Zhuang, Z. H.; Yang, Y. L. BMC Biotechnol. 2012, 12, 36 . 